\title{
Anti-inflammatory effects of triptolide improve left ventricular function in a rat model of diabetic cardiomyopathy
}

\author{
He-Ling Wen ${ }^{1,2}$, Zhong-Shu Liang ${ }^{1}$, Rui Zhang ${ }^{3}$ and Kan Yang ${ }^{1 *}$
}

\begin{abstract}
Aims: Given the importance of inflammation in the onset and progression of diabetic cardiomyopathy, we investigated the potential protective effects of triptolide, an anti-inflammatory agent, in streptozotocin-induced diabetic rat model and in $\mathrm{H} 9 \mathrm{c} 2$ rat cardiac cells exposed to high glucose.

Methods and results: Diabetic rats were treated with triptolide (100, 200, or $400 \mu \mathrm{g} / \mathrm{kg} /$ day respectively) for 6 weeks. At the end of this study, after cardiac function measurements were performed, rats were sacrificed and their hearts were harvested for further histologic and molecular biologic analysis. Enhanced activity and expression of nuclear factor-kappaB (NF-kB) p65 in diabetic hearts were associated with increased inflammatory response, as demonstrated by increased pro-inflammatory cytokines, cell adhesion molecules and invading inflammatory cells, as well as increased fibrosis, in line with impaired left ventricular function. Triptolide attenuated these morphofunctional alterations. Furthermore, triptolide $(20 \mathrm{ng} / \mathrm{ml})$ also attenuated high glucose-induced inflammation in $\mathrm{H} 9 \mathrm{c} 2$ rat cardiac cells.
\end{abstract}

Conclusion: Our data demonstrate that anti-inflammatory effects of triptolide involving the NF-KB signaling pathway can improve left ventricular function under diabetic conditions, suggesting triptolide treatment might be beneficial in diabetic cardiomyopathy.

Keywords: Triptolide, Diabetic cardiomyopathy, NF-kB, Inflammation

\section{Introduction}

Diabetic cardiomyopathy, one of the leading cardiovascular complications in diabetic patients, has gained much interest due to its subsequent heart failure and eventually increased mortality. Over the last decades, accumulating evidence from both clinical data and animal models shows that diverse mechanisms are involved in the development of diabetic cardiomyopathy, including microangiopathy, alterations in substrate metabolism, oxidative damage, cardiac inflammation and fibrosis [1-4]. Among these abnormalities, the unresolved inflammatory response plays a key role in the onset and progression of diabetic cardiomyopathy $[5,6]$. Chronic inflammation could directly and indirectly cause cardiac tissue injury such as myocardial fibrosis, necrosis and apoptosis, which inevitably leads to

\footnotetext{
* Correspondence: kanyang0731@163.com

'Department of Cardiology, The Third Xiangya Hospital of Central South University, No. 138 Tongzipo Road, Changsha, Hunan 410013, P.R.China Full list of author information is available at the end of the article
}

left ventricular (LV) diastolic and then systolic dysfunction. The recognition of the inflammatory basis for diabetic cardiomyopathy may greatly contribute to the management of this disease.

Tripterygium wilfordii Hook $F$ (TwHF), due to its wellestablished cost-effect ratio, has been used in traditional Chinese medicine to treat autoimmune and inflammatory diseases for centuries $[7,8]$. Triptolide (TP), a purified component of TwHF, accounts for its major bioactive effect. Randomized controlled clinical trails in the United States have shown the safety and efficacy of triptolide in treating patients with rheumatoid arthritis [9-11]. Triptolide has also been used to treat other immune-mediated inflammatory diseases, such as complex nephritis and systemic lupus erythematosus. In addition, it has been demonstrated triptolide can effectively prolong the cardiac allograft survival $[12,13]$, so the clinical applications of triptolide have been extended to organ transplantation. 
A recent study has shown that triptolide, through suppressing renal inflammation and oxidative stress, prevents diabetic nephropathy progression [14]. Therefore, on the basis of the above considerations, we hypothesized that triptolide may exert protective effects in a rat model of diabetic cardiomyopathy and in cultured cardiomyocytes exposed to high glucose (HG).

\section{Methods}

\section{Animal model and treatment}

Diabetes mellitus (DM) was induced in 8-week-old male Sprague-Dawley (SD) rats (Central South University Animal Centre, China) by a single intraperitoneal injection of streptozocin (STZ, $70 \mathrm{mg} / \mathrm{kg}$, dissolved in $0.1 \mathrm{M}$ sodium citrate buffer, $\mathrm{pH}$ 4.5; Sigma, USA) after starvation overnight. Three days and one week after the injection, random blood glucose level was measured using Onetouch SureStep glucometer (LifeScan, USA) by tail vein blood sampling. Only rats with blood glucose level > $16.7 \mathrm{mmol} / \mathrm{l}$ in both tests were selected in this study. These 1-week diabetic rats were randomly divided into four groups $(\mathrm{n}=10$ each): three diabetic groups treated with triptolide $(100,200$, or $400 \mu \mathrm{g} / \mathrm{kg} /$ day respectively) and one diabetic group treated with vehicle. In order to verify the potential side effects of triptolide, one sex- and age-matched non-diabetic group (SD rats injected with sodium citrate buffer only, $\mathrm{n}=10$ ) was treated with high-dose triptolide $(400 \mu \mathrm{g} / \mathrm{kg} /$ day). Triptolide (Chinese National Institute for the Control of Pharmaceutical and Biological Products, China), dissolved in dimethylsulfoxide (DMSO; Sigma, USA), was given by daily gastric gavage for 6 weeks. Another sex- and age-matched nondiabetic group $(n=10)$ was referred to as the control group. Rats were kept in the laminar flow cages on a $12 \mathrm{~h} /$ $12 \mathrm{~h}$ dark/light cycle with free access to standard chow and tap water. At the end of this study, after cardiac function measurements were obtained, rats were sacrificed and their hearts were harvested for further histologic and molecular biologic analysis. In addition, blood from the aorta was collected for the determination of liver and renal functions, as well as serum marker of cardiac damage. The investigation was approved by the Institutional Animal Care and Use Committee of Central South University.

\section{Cardiac function measurement}

Echocardiography was performed in all rats using GE Vivid 7 ultrasound system with a $10-\mathrm{MHz}$ transducer (General Electric, USA). During the procedure, rats were anesthetized with intraperitoneal injection of pentobarbital $(50 \mathrm{mg} / \mathrm{kg}$ ) and placed in the supine position. LV end-diastolic dimension (LVEDD) and LV end-systolic dimension (LVESD) were measured on the parasternal LV long axis view. These chamber dimensions were indexed to body weight. LV ejection fraction (LVEF) and fractional shortening (FS) were calculated by assuming a spherical LV geometry with the algorithms of ultrasound system. The parameters above were measured at least three times and averaged. All measurements were performed by an experienced investigator who was blinded to the grouping and treatment information.

\section{Histopathology and immunohistochemistry}

Heart samples were fixed in $4 \%$ buffered paraformaldehyde solution and embedded in paraffin. The $5 \mu \mathrm{m}$ tissue sections were stained with Sirius red, assessing for total cardiac collagen content. For immunohistochemistry, after blocking endogenous peroxidase activity with $3 \%$ hydrogen peroxide, the sections were incubated with blocking buffer to further block unspecific sites. Staining was performed with the following primary antibodies at the given dilution overnight at $4^{\circ} \mathrm{C}$ : collagen $\mathrm{I}(\mathrm{Col} \mathrm{I}, 1$ : 200; Abcam, USA), collagen III (Col III, 1: 200; Abcam, USA), CD68 (1: 100; Adb Serotec, Germany) and CD3 (1: 300; Adb Serotec, Germany). After washing, the sections were incubated with biotin-labeled secondary antibody (1: 400; Vector lab, USA) for 1 hour at room temperature followed by color development with DAB kit (Vector lab, USA). Immunohistochemical staining was quantified with Image Pro Plus 6.0 software on 10 fields of the left ventricle.

\section{Quantitative real-time RT-PCR}

Quantitative real-time RT-PCR was performed to assess transcript levels of tumor necrosis factor- $\alpha$ (TNF- $\alpha$ ), interleukin-1 $\beta$ (IL-1 $\beta$ ), intercellular adhesion molecule-1 (ICAM-1), vascular cell adhesion molecule-1 (VCAM-1) and nuclear factor-kappaB (NF-kB) p65. After RNA extraction, the concentration and integrity of the RNA was determined. Total RNA was then reverse-transcribed to cDNA, and the target genes were amplified using the type of CFX96 real-time PCR system (Bio-Rad, USA). The amplification conditions were set as followings: initial hold steps $\left(50^{\circ} \mathrm{C}\right.$ for $2 \mathrm{~min}$, then $95^{\circ} \mathrm{C}$ for $\left.10 \mathrm{~min}\right)$ and 40 cycles of a two-step PCR $\left(95^{\circ} \mathrm{C}\right.$ for $15 \mathrm{~s}$ and $60^{\circ} \mathrm{C}$ for $\left.1 \mathrm{~min}\right)$. The fold change of the target PCR product was calculated after adjusting for $\beta$-actin using the comparative delta-delta $C_{t}$ method. The primers used in this study were obtained from Genscript Corp (Nanjing, China), and its sequences were as follows: for TNF- $\alpha$ 5'-TGACCCCCATTACT CTGACC-3' and 5'-GGCCACTACTTCAGCGTCTC-3'; for IL-1 $\beta 5^{\prime}$-CTCCATGAGCTTTGTACAAGG-3' and $5^{\prime}$ TGCTGATGTACCAGTTGGGG-3'; for ICAM-1 $5^{\prime}$ GTCTCATGCCCGTGAAATTATG-3' and 5'-CATTTT CTCCCAGGCATTCTCT-3'; for VCAM-1 5'-GGAGGT CTACTCATTCCCTGAAGA-3' ${ }^{\prime}$ and $5^{\prime}$-ACCGTGCAGT TGACAGTGACA-3'; for NF-kB p65 5'-CTCCCGGG CAGGTCTCAGC-3' and 5'-GAAACGCATGCCCCGCT 
GCT-3'; for $\beta$-actin $5^{\prime}$-CATCCTGCGTCTGGACCTGG$3^{\prime}$ and $5^{\prime}$-TAATGTCACGCACGATTTCC- ${ }^{\prime}$.

\section{Western blot}

Western blot was used to quantify protein levels of TNF- $\alpha$, IL-1 $\beta$, ICAM-1, VCAM-1 and NF-kB p65. After the measurement of protein concentration, equal amount of protein was separated by 10\% SDS-PAGE and transferred to polyvinylidene fluoride membranes. The membranes were blocked with 5\% nonfat milk in TBS buffer. Then different primary antibodies, including TNF- $\alpha$ (Bioworld, USA), IL$1 \beta$ (Proteintech, USA), ICAM-1(Abcam, USA), VCAM-1 (Abcam, USA) and NF-kB p65 (Bioworld, USA), were added at a dilution of 1:1,000 overnight at $4^{\circ} \mathrm{C}$. After washing, the membranes were incubated with horseradish peroxidase-conjugated secondary antibody (1: 4,000; Proteintech, USA) for 1 hour at room temperature. The blots were visualized using ECL kit (Thermo pierce, USA). $\beta$-actin was used as a loading control. The density of bands was quantified with Image Pro Plus 6.0 software.

\section{TransAM ${ }^{\mathrm{TM}}$ NF-KB p65 Elisa}

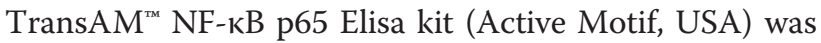
tested for the DNA-binding activity of free NF- $\mathrm{kB}$ p65 in nuclear extracts. Nuclear protein extraction and NF- $\mathrm{kB}$ p65 activation assay were performed according to the manufacturer's instructions.

\section{Cell culture}

H9c2 rat cardiac cell line (ATCC, USA) was cultured in DMEM in $5 \% \mathrm{CO}_{2}$ at $37^{\circ} \mathrm{C}$. The cells were divided into three groups and cultured for 48 hours: (a) D-glucose (5.5 mmol/l); (b) high D-glucose (33 mmol/l); (c) costimulated with high D-glucose $(33 \mathrm{mmol} / \mathrm{l})$ and triptolide $(20 \mathrm{ng} / \mathrm{ml})$. Then, the cells were harvested and processed for the molecular biologic assay. The mRNA and protein expressions of TNF- $\alpha$ and NF- $\mathrm{kB}$ p65 were analysed by quantitative real-time RT-PCR and western blot, respectively. The activity of NF-кB p65 was assessed by TransAM $^{\mathrm{tw}}$ NF- $\mathrm{kB}$ p65 Elisa.

\section{Statistical analysis}

SPSS software version 18.0 was used for statistical analysis. Continuous variables were presented as mean \pm standard deviation (SD). Comparisons of continuous data were carried out with one-way ANOVA and post hoc analysis with Bonferroni test. When heterogeneity of variance was present, comparisons were performed with Mann-Whitney test, followed by post hoc analysis with Kruskal-Wallis test. A value of $\mathrm{P}<0.05$ was considered statistically significant.

\section{Results}

\section{Characterization of animal groups}

At the end of the study, the untreated and triptolidetreatment diabetic groups displayed severe hyperglycemia and higher heart weight to body weight ratio compared with non-diabetic groups. The increased ratio in diabetic groups was mainly due to the significantly smaller body weight of these animals. Triptolide treatment did not affect the above metabolic parameters in either non-diabetic or diabetic groups (Table 1).

\section{Cardiac performance}

Although echocardiography did not show any differences in LV end diastolic and systolic dimensions among groups, the LV dimension indices were significantly higher in diabetic groups, indicating LV dilatation in diabetic rats. Importantly, triptolide treatment significantly improved LV dysfunction in diabetic rats, as shown by increased LVEF. And FS in triptolide-treatment diabetic groups also showed the upward trend compared with the untreated diabetic group, but the difference did not reach statistical significance (Table 2 ).

\section{Cardiac fibrosis}

Since collagen deposition influences the passive mechanical properties of the myocardium and then affects the cardiac performance, we observed changes of total collagen, collagen I and collagen III content in the rat hearts. Total collagen content, measured by Sirius red staining, was significantly increased in both interstitial and perivascular sites in diabetic rats compared with controls. Accordingly, collagen I and collagen III, which accounted for $90 \%$ of cardiac collagen, were increased in these rats. Triptolide treatment attenuated, but did not normalize, diabeticinduced cardiac fibrosis (Figure 1).

Table 1 Animal characterization

\begin{tabular}{lllllll}
\hline & Con & TP & DM & DM + TP,L & DM + TP,M & DM + TP,H \\
\hline Glucose, mmol/l & $6.6 \pm 1.9$ & $5.9 \pm 1.4$ & $32.2 \pm 2.5^{*}$ & $32.1 \pm 3.5^{*}$ & $30.8 \pm 3.0^{*}$ & $32.6 \pm 2.6^{*}$ \\
BW, g & $464.0 \pm 21.2$ & $468.0 \pm 19.6$ & $216.3 \pm 21.7^{*}$ & $234.8 \pm 37.5^{*}$ & $235.7 \pm 30.5^{*}$ & $224.3 \pm 29.3^{*}$ \\
HW, $\mathrm{mg}$ & $1183.3 \pm 14.2$ & $1202.5 \pm 12.4$ & $758.6 \pm 13.6^{*}$ & $762.3 \pm 15.3^{*}$ & $771.3 \pm 14.7^{*}$ & $734.8 \pm 13.2^{*}$ \\
HW/BW, mg/g & $2.55 \pm 0.32$ & $2.56 \pm 0.23$ & $3.49 \pm 0.35^{*}$ & $3.24 \pm 0.41^{*}$ & $3.25 \pm 0.34^{*}$ & $3.28 \pm 0.42^{*}$ \\
\hline
\end{tabular}

$B W$ body weight, $H W$ heart weight, $T P, L$ low-dose triptolide $(100 \mu \mathrm{g} / \mathrm{kg} /$ day), $T P, M$ medium-dose triptolide $(200 \mu \mathrm{g} / \mathrm{kg} /$ day), $T P, H$ high-dose triptolide $(400 \mu \mathrm{g} / \mathrm{kg} /$ day). ${ }^{*} \mathrm{P}<0.05$ versus Con; ${ }^{*} \mathrm{P}<0.05$ versus $\mathrm{DM}$. 
Table 2 Echocardiographic parameters

\begin{tabular}{lllllll}
\hline & Con & TP & DM & DM + TP,L & DM + TP,M & DM + TP,H \\
\hline LVEDD, mm & $6.5 \pm 0.5$ & $6.6 \pm 0.5$ & $5.7 \pm 0.8$ & $5.9 \pm 0.4$ & $5.5 \pm 0.7$ & $5.3 \pm 1.1$ \\
LVEDD index, um/g & $14.3 \pm 1.2$ & $14.4 \pm 1.1$ & $23.9 \pm 3.4^{*}$ & $22.0 \pm 2.9^{*}$ & $22.2 \pm 2.1^{*}$ & $21.1 \pm 4.6^{*}$ \\
LVESD, mm & $3.8 \pm 0.3$ & $3.8 \pm 0.4$ & $3.8 \pm 0.6$ & $3.7 \pm 0.3$ & $3.2 \pm 0.3$ & $3.2 \pm 0.9$ \\
LVESD index, um/g & $8.3 \pm 0.7$ & $8.2 \pm 0.9$ & $16.0 \pm 2.5^{*}$ & $13.7 \pm 2.2^{*}$ & $13.0 \pm 1.1$ & $12.6 \pm 3.4$ \\
LVEF,\% & $78.2 \pm 2.6$ & $77.5 \pm 3.1$ & $67.8 \pm 2.6^{*}$ & $73.7 \pm 2.5$ & $74.8 \pm 3.8^{\#}$ & $74.4 \pm 3.8^{\#}$ \\
FS,\% & $43.2 \pm 2.6$ & $42.7 \pm 3.3$ & $35.0 \pm 1.6^{*}$ & $39.5 \pm 2.4$ & $40.8 \pm 3.3$ & $40.0 \pm 3.7$ \\
\hline
\end{tabular}

LVEDD left ventricular end-diastolic dimension, LVESD left ventricular end-systolic dimension, LVEF left ventricular ejection fraction, FS fractional shortening. TP, $L$ low-dose triptolide $\left(100 \mu \mathrm{g} / \mathrm{kg} /\right.$ day), TP, M medium-dose triptolide $(200 \mu \mathrm{g} / \mathrm{kg} /$ day $) ; T P, H$ high-dose triptolide $(400 \mu \mathrm{g} / \mathrm{kg} / \mathrm{day}) .{ }^{*} P<0.05$ versus Con; ${ }^{\#} P<0.05$ versus DM.

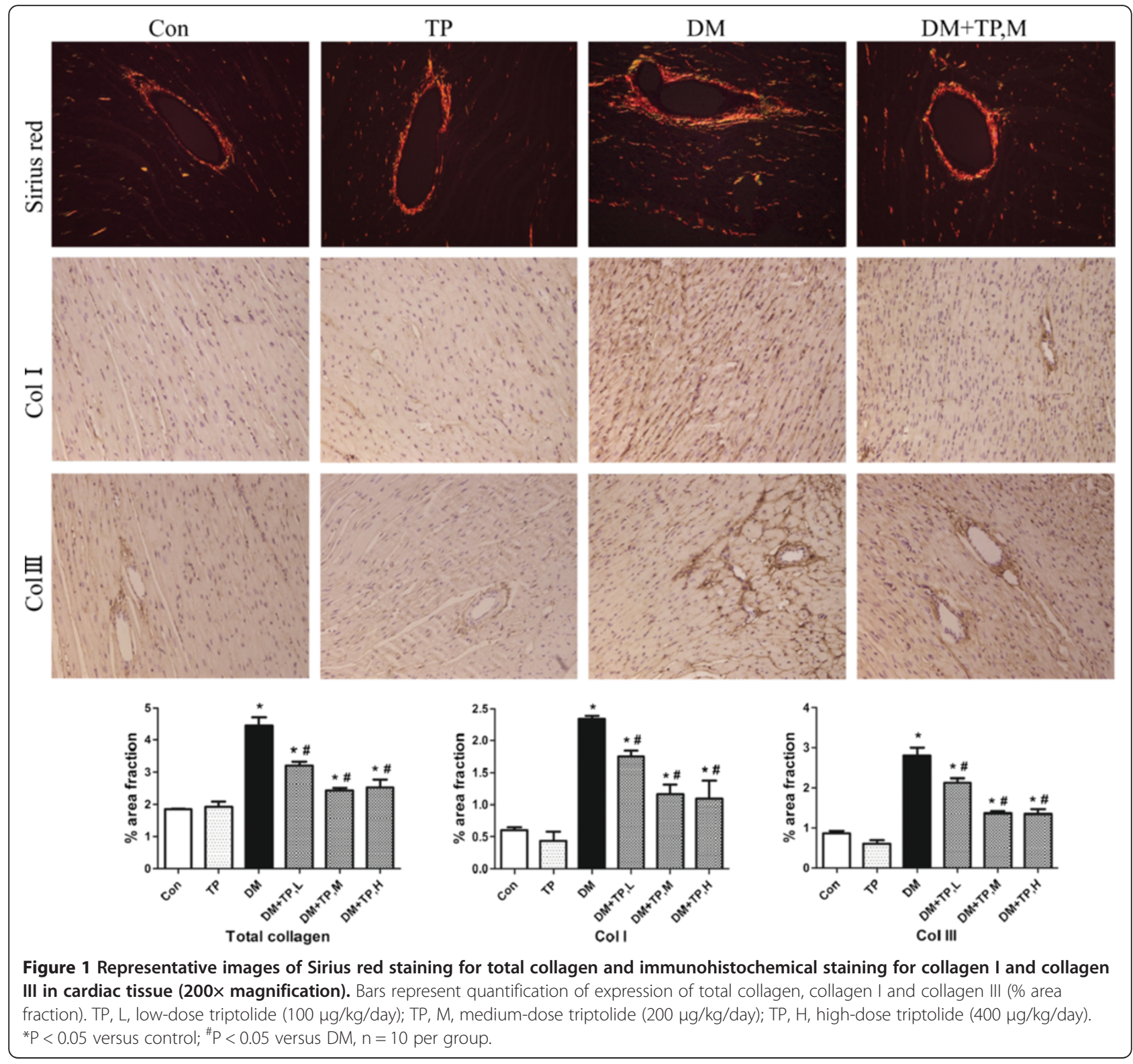




\section{Cardiac inflammation}

Given the importance of inflammation in the progression of diabetic cardiomyopathy, we analysed the expression of key pro-inflammatory cytokines and cell adhesion molecules, as well as the infiltration of inflammatory cells, in the cardiac tissue. The mRNA and protein levels of TNF$\alpha$ and IL-1 $\beta$ in diabetic rats revealed a significant increase compared with controls. Enhanced expression of ICAM-1 and VCAM-1 was also observed in these rats. In agreement with increased inflammatory mediators, immunohistological staining demonstrated a higher recruitment of macrophages and T lymphocytes (CD68+ and CD3+ cells, respectively) in diabetic rat hearts. Triptolide treatment significantly attenuated the aforementioned cardiac inflammation. It should be noted that, besides its prominent anti-inflammatory effect, triptolide as an immunoregulatory agent also showed the immunosuppressive activity, thus leading to reduced expression of inflammatory mediators in non-diabetic rats (Figure 2, Figure $3 \mathrm{~A}$ to $3 \mathrm{D}, 3 \mathrm{~F}$ and $3 \mathrm{I})$.

\section{Cardiac activity and expression of NF-KB p65}

The transcription factor NF- $k B$ plays a crucial role in regulating a variety of genes involved in inflammatory response. Therefore, we further examined the activity and the expression of NF- $\mathrm{kB}$ p65 in cardiac tissue. Consistent with the upregulated inflammatory mediators, the DNA-binding activity of free NF-kB p65 in nuclear extracts of diabetic hearts was significantly increased compared with controls. And the mRNA and protein levels of NF-кB p65 were enhanced in parallel. Triptolide treatment not only inhibited the activation of $N F-\kappa B$ p65, but also reduced the mRNA and protein expressions of NF-kB p65 (Figure 3E, 3J and 3K)

\section{Safety of triptolide treatment}

To assess the safety of triptolide treatment, we tested several main indices of liver and renal functions, as well as serum marker of cardiac damage. The untreated and triptolide-treatment diabetic groups showed the elevated serum alanine aminotransferase (ALT) level compared

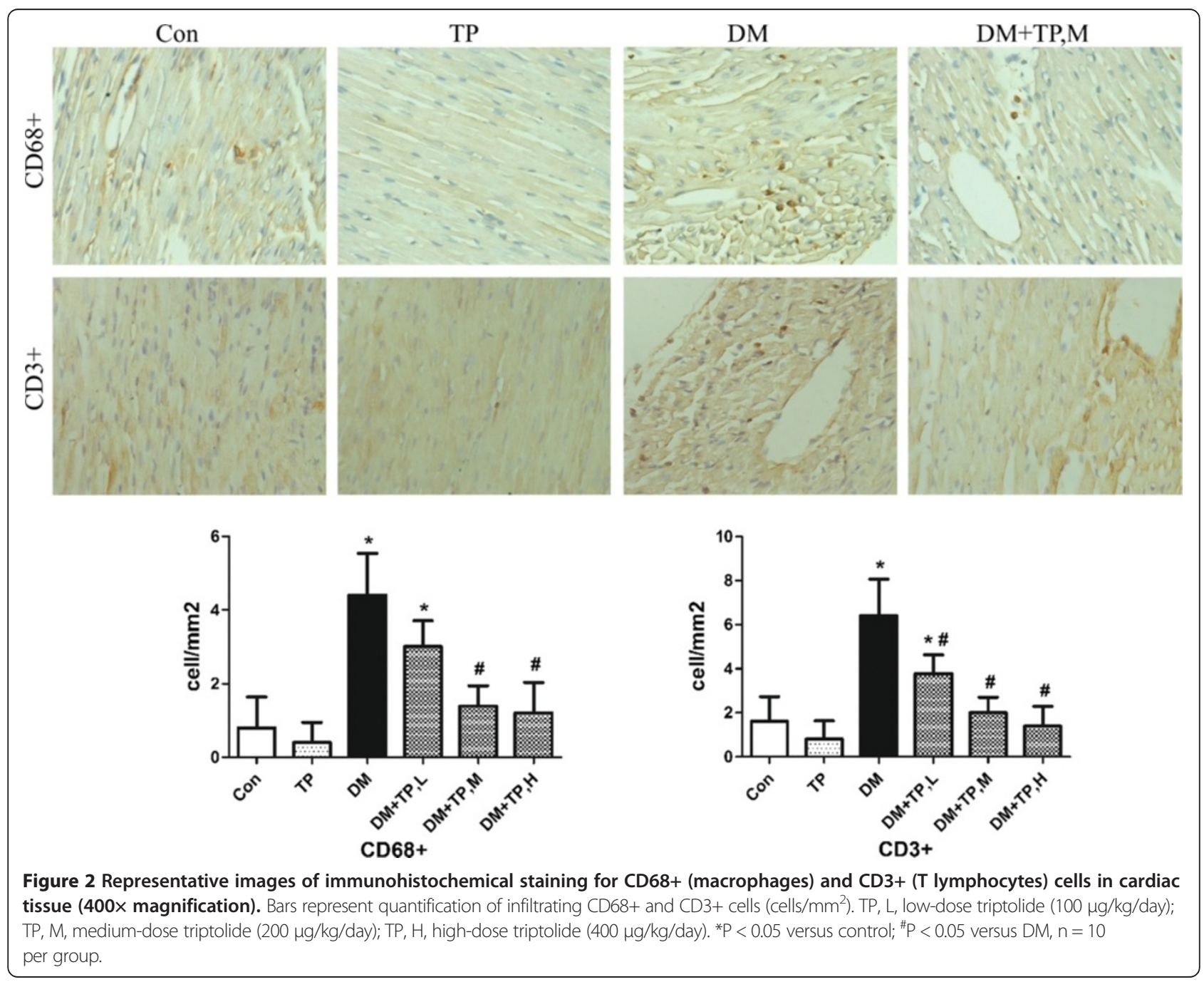



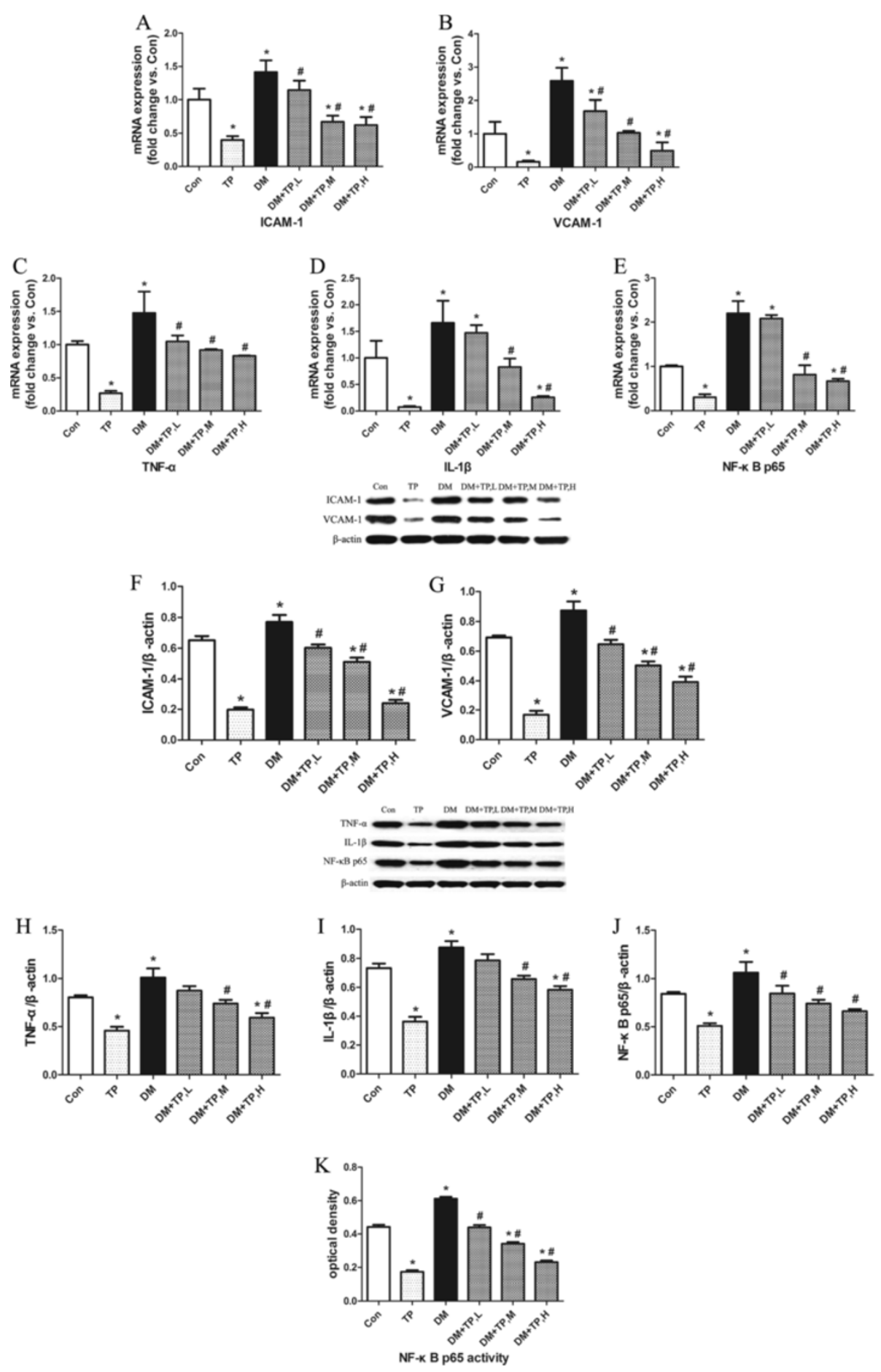

Figure 3 Triptolide attenuated diabetes-induced cardiac inflammation. (A-E) mRNA expressions of TNF- $\alpha$, IL-1 $\beta$, ICAM-1, VCAM-1 and NF-KB p65, as determined by quantitative real-time RT-PCR. (F-J) protein expressions of TNF- $\alpha$, IL-1 $\beta$, ICAM-1, VCAM-1 and NF-kB p65, as determined by western blot. (K) DNA-binding activity of free NF-KB p65 in nuclear extracts, as determined by TransAM ${ }^{T M}$ NF-KB p65 Elisa. TP, L, low-dose triptolide

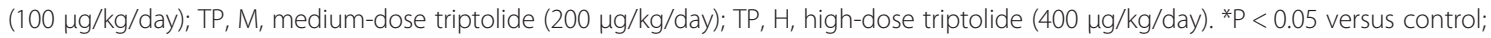
${ }^{\#} \mathrm{P}<0.05$ versus $\mathrm{DM}, \mathrm{n}=10$ per group. 
Table 3 Safety of triptolide treatment

\begin{tabular}{lllllll}
\hline & Con & TP & DM & DM + TP,L & DM + TP,M & DM + TP,H \\
\hline ALT, U/I & $44.7 \pm 13.3$ & $42.2 \pm 12.1$ & $72.4 \pm 13.5^{*}$ & $76.5 \pm 20.1^{*}$ & $84.5 \pm 13.6^{*}$ & $89.6 \pm 11.5^{*}$ \\
AST, U/I & $110.0 \pm 41.0$ & $114.0 \pm 46.1$ & $144.0 \pm 59.0$ & $141.2 \pm 43.6$ & $167.7 \pm 57.3$ & $167.4 \pm 60.2$ \\
Cr, $\mu \mathrm{mol} / \mathrm{I}$ & $53.3 \pm 13.8$ & $51.5 \pm 11.7$ & $56.4 \pm 15.4$ & $41.8 \pm 13.1$ & $42.6 \pm 8.2$ & $40.2 \pm 7.4$ \\
CK-MB, U/I & $593.2 \pm 158.1$ & $538.2 \pm 234.7$ & $714.7 \pm 132.3$ & $322.0 \pm 53.3^{* \#}$ & $450.2 \pm 90.8^{\#}$ & $517.4 \pm 79.7$ \\
\hline
\end{tabular}

$T P$, $L$ low-dose triptolide $(100 \mu \mathrm{g} / \mathrm{kg} / \mathrm{day}), T P, M$ medium-dose triptolide $\left(200 \mu \mathrm{g} / \mathrm{kg} /\right.$ day), $T P, H$ high-dose triptolide $\left(400 \mu \mathrm{g} / \mathrm{kg} /\right.$ day). ${ }^{*} \mathrm{P}<0.05 \mathrm{versus}$ Con; ${ }^{\#} \mathrm{P}<0.05$ versus DM.

with control group. No significant difference in aspartate aminotransferase (AST) and creatinine (Cr) levels was observed among groups. Serum creatine kinase-myoglobin (CK-MB) level in triptolide-treatment diabetic groups was not upregulted, even showed the downward trend compared with the untreated diabetic group (Table 3).

\section{HG-induced inflammation in $\mathrm{H} 9 \mathrm{c} 2$ cells}

H9c2 cells incubated with HG for 48 hours displayed overt inflammatory response, as shown by the enhanced activity of NF- $\mathrm{kB}$ p65, as well as increased mRNA and protein expressions of TNF- $\alpha$ and NF- $\mathrm{kB}$ p65. Triptolide markedly inhibited HG-induced inflammation (Figure 4).

\section{Discussion}

To our knowledge, this study is the first to reveal that chronic treatment with triptolide attenuates cardiac inflammation and myocardial fibrosis, resulting in improved $\mathrm{LV}$ function in a rat model of diabetic cardiomyopathy.

\section{Cardiac inflammation in diabetic cardiomyopathy}

Consistent with previous study, diabetic rats in our study displayed overt intramyocardial inflammation 7 weeks after STZ injection [15], as evidenced by enhanced activity and expression of NF- $\mathrm{kB}$ p65, thus leading to increased levels of cardiac pro-inflammatory cytokines (TNF- $\alpha$, IL-1 $\beta$ ), enhanced expressions of cell adhesion molecules (ICAM-1, VCAM-1), and activated invading immunocompetent cells (macrophages, $\mathrm{T}$ lymphocytes). In addition, cardiac collagen content (total collagen, collagen I and collagen III) was also significantly increased in these untreated rats. Consequently, these abnormal structural alterations in diabetic rats led to impaired cardiac performance, i.e. increased LV dimension indices, reduced LVEF and FS.

Although some researchers reported myocardial inflammation is not present in long-term experimental diabetic model [16], the notion that inflammation is an early response to diabetic insult is widely accepted. And once the advanced structural alterations are formed, the prognosis of diabetic cardiomyopathy is very poor. Therefore, the rationale supporting anti-inflammatory agents' early usage in diabetic cardiomyopathy is 3 -fold. First, inflammation characterized by elevated inflammatory cytokine production exists not only in the myocardium of animal models $[15,17,18]$, but also in the serum of diabetic patients, even in those patients with good glycemic control [19]. Second, it has been demonstrated that inflammatory cytokines (TNF- $\alpha$, IL-1 $\beta$ ) participate in the development of LV dysfunction, and negatively correlate with LV contractility $[20,21]$. Inflammatory cytokines can attenuate cardiomyocyte contractility directly through the immediate reduction of systolic cytosolic calcium and indirectly through attenuation of myofilament calcium sensitivity [22], and this detrimental effect may be reversible by clearance of the cytokine exposure. Last but not the least, though the Framingham study indicated poor glycemic control was associated with an increased risk of heart failure [23], the ADVANCE (Action in Diabetes and Vascular Disease) trail and a meta-analysis unexpectedly showed intensive glycemic control did not reduce the occurrence of heart failure $[24,25]$. Furthermore, heart failure progression is not blocked by optimal therapy with angiotensinconverting enzyme inhibitors and beta-blockers.

As the most extensively studied cytokine, TNF- $\alpha$ is a noteworthy pro-inflammatory cytokine with various pathogenic effects. On one side, TNF- $\alpha$ is a valuable biomarker, for its correlation with enhanced brain natriuretic peptide and adverse clinical outcome in patients with heart failure $[26,27]$. On the other side, TNF- $\alpha$ is a strong mediator in the progression of heart failure. TNF- $\alpha$ not only exacerbates inflammatory response through acting as a signal amplifier to induce other inflammatory cytokines production, but also contributes to myocardial hypertrophy and fibrosis, leading to LV remodeling and dysfunction [28]. Thus, TNF- $\alpha$ may serve as a potential target in preventing LV dysfunction therapy. Although the result of anti-TNF therapy is encouraging in animal models, the anti-TNF therapy in clinical trials does not show benefits in preventing LV dysfunction $[29,30]$. One explanation for the negative result is that targeting a single cytokine is not an effective approach under a complex network of inflammatory signaling pathways, as other redundant cytokines may continue to propagate the inflammatory response. A more robust and comprehensive strategy would be to target a more central locus, such as NF- $\mathrm{kB}$, which integrates signals from multiple inflammatory mediators $[2,5]$. 

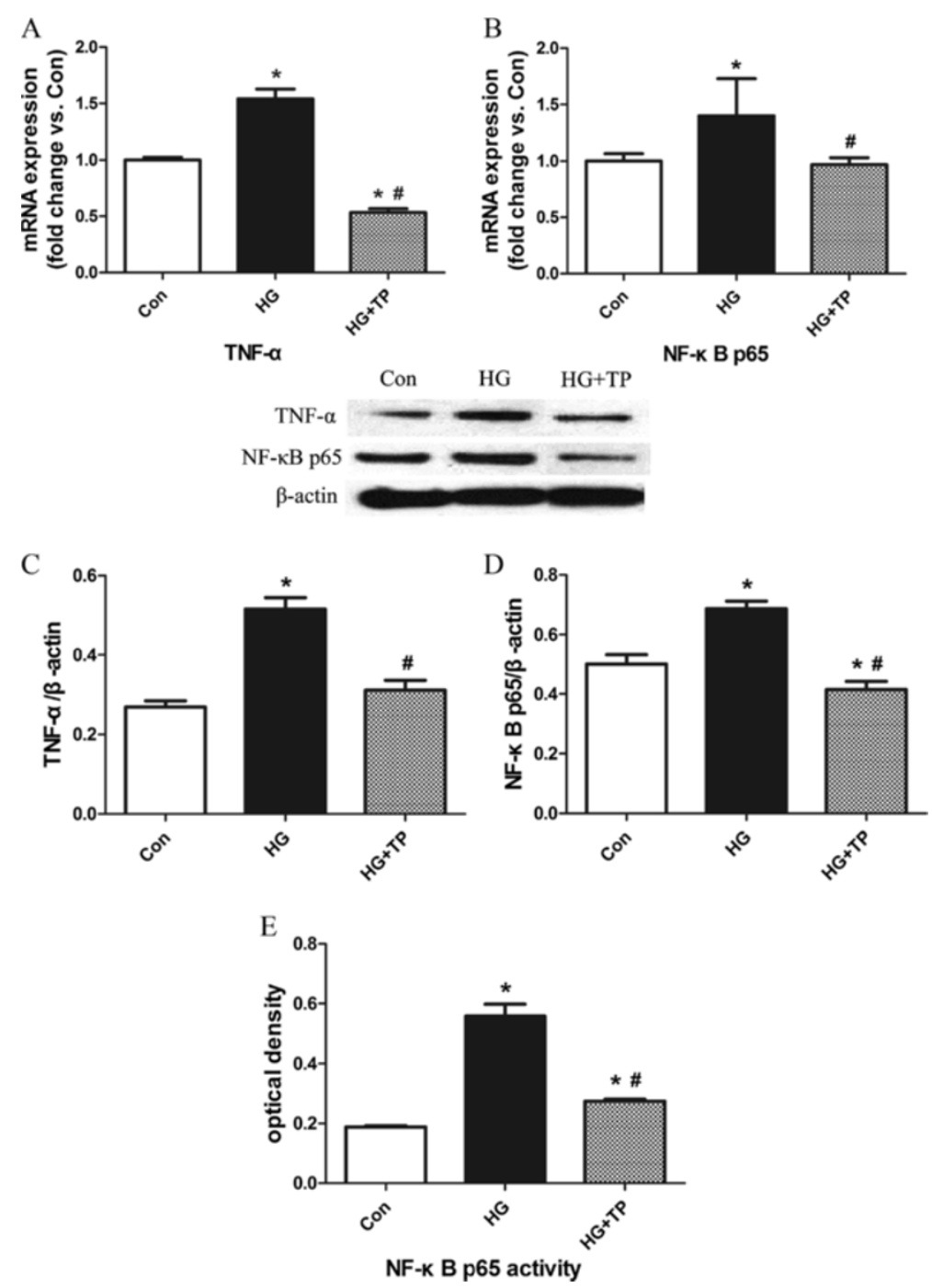

Figure 4 Triptolide attenuated HG-induced inflammation in H9c2 cells. (A, B) mRNA expressions of TNF-a and NF-KB p65, as determined by quantitative real-time RT-PCR. (C, D) protein expressions of TNF-a and NF-KB p65, as determined by western blot. (E) DNA-binding activity of free

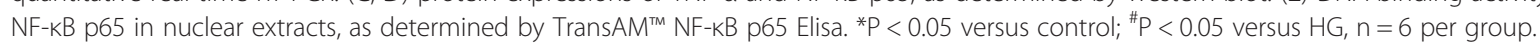

\section{Therapeutic effect of triptolide}

In the current study, we observed treatment with triptolide significantly attenuated cardiac inflammation and fibrosis through suppressing the activity and the expression of $\mathrm{NF}-\mathrm{kB}$ in a rat model of diabetic cardiomyopathy. It is reasonable to suggest these morpho-functional changes improved, although not completely normalized, LV systolic function. In H9c2 cells exposed to HG, triptolide also markedly inhibited NF-kB activation and attenuated HGinduced inflammation. The cardioprotective effects of triptolide may be mediated, at least in part, through NF- $\mathrm{kB}$ signaling pathway.

As shown in the present and in previous studies, triptolide inhibited the activation and the expression of NF- $\mathrm{kB}$ in vitro and in vivo [31-34]. NF- $\mathrm{kB}$ is a pleiotropic transcription factor that controls the expression of several target genes, mainly of them involved in inflammation. Under hyperglycemic condition, the DNAbinding activity of NF-kB p65 was enhanced, and its mRNA and protein expressions were also upregulated. The NF- $\mathrm{kB}$ activation led to the increased expression of inflammatory mediators, including pro-inflammatory cytokines (TNF- $\alpha$, IL-1 $\beta$ ) and cell adhesion molecules (ICAM-1, VCAM-1), which contributed to the recruitment and activation of inflammatory cells (macrophages, $\mathrm{T}$ lymphocytes) in cardiac tissue. And some of these cytokines, such as TNF- $\alpha$ and IL- $1 \beta$, could further stimulate NF- $\mathrm{BB}$ activation as a positive feedback loop. Collectively, these inflammatory mediators cooperated closely to initiate and maintain cardiac inflammation in diabetic rats. However, 6 weeks of triptolide treatment significantly inhibited the activation and the expression 
of NF- $\mathrm{kB}$, as well as the expression of NF-kB-dependent inflammatory mediators in diabetic hearts.

In our study, increased cardiac fibrosis was noticed in STZ diabetic rats and effectively ameliorated by triptolide treatment. In addition to suppress the pro-fibrotic action of NF- $\mathrm{kB}$ [5], the attenuation of cardiac inflammation may be another mechanism of triptolide's anti-fibrotic effects, since cardiac fibrosis is also partly mediated by some profibrotic inflammatory cytokine, such as TNF- $\alpha$ and IL-1 $\beta$. Furthermore, hyperglycemia induced oxidative stress is an important pathogenic factor in the development of cardiac fibrosis. There is an increasing interest in suppressing oxidative stress as an effective strategy for reducing cardiac fibrosis $[35,36]$. And it has been demonstrated that triptolide can significantly reduce oxidative stress [33,34]. Thus, we may speculate that the anti-fibrotic effects of triptolide are also related to its inhibitory effect on oxidative stress. However, further investigation must be performed to elucidate the exact anti-fibrotic mechanism of triptolide under diabetic conditions.

Although several researchers have reported that triptolide does not affect NF- $\mathrm{kB}$ DNA-binding activity [37], our findings demonstrated triptolide could inhibit hyperglycemic-induced NF- $\mathrm{BB}$ activation both in vitro and in vivo, confirmed by TransAM ${ }^{\mathrm{Tn}} \mathrm{NF}-\mathrm{\kappa B}$ p65 Elisa assay. And our results are consistent with the prevailing view regarding the effect of triptolide on NF- $\mathrm{kB}$ activity [8]. One plausible explanation for this discrepancy is differences in cell types, animal models, or experimental methodologies.

The dosage of triptolide was selected based on our pilot study and other studies [31,32]. It should be noted that the cardioprotective effects of triptolide under diabetic condition was not exactly dose-dependent. One possibility is that the anti-inflammatory potency of triptolide at the dosage of $200-400 \mu \mathrm{g} / \mathrm{kg} /$ day reaches a plateau. The safety of triptolide treatment was confirmed by serum ALT, AST, Cr and CK-MB level assay. Although the untreated and triptolide-treatment diabetic groups showed the increased ALT level compared with control group, triptolide-treatment in non-diabetic rats did not upregulate ALT level. And no significant difference in AST and Cr levels was observed among groups. Moreover, triptolide treatment did not upregulate CKMB level. Therefore, we infer that the increased ALT level in diabetic rats was due to diabetic-induced liver damage, while triptolide itself in our study did not show liver, kidney or cardiac toxicity.

\section{Study limitations}

Although STZ is widely used to induce diabetic animal model, a few reports have indicated that STZ itself may cause cardiac morpho-functional abnormalities [38]. And the STZ-model is associated with severe hyperglycemia and hypoinsulinemia, which is not encountered in patients with type 1 diabetes receiving exogenous insulin. However, in clinical setting diabetic patients are always accompanied with comorbidities such as hypertension and atherosclerosis, the classical STZ-model is considered as an ideal model for experimental diabetic cardiomyopathy due to its relative resistance to develop hypertension and atherosclerosis [39-41]. Therefore, this model is particular useful in exploring the effect of hyperglycemia alone on cardiac tissue, that is, the underlying mechanism of diabetic cardiomyopathy. Caution should be taken when extrapolating our findings in STZ-animal models to diabetic patients. Although triptolide treatment in non-diabetic rats did not affect cardiac performance and other metabolic parameters, the longterm consequences of its potential immunosuppressive property should be further examined with care. In addition, further study is required to evaluate the therapeutic effect of triptolide post-treatment after the establishment of diabetic cardiomyopathy.

\section{Conclusion}

In conclusion, triptolide treatment significantly attenuates cardiac inflammation and fibrosis through suppressing the activity and the expression of NF- $\mathrm{KB}$, resulting in improved LV function in experimental diabetic cardiomyopathy. Our data demonstrate that triptolide might be potentially used in conjunction with current glycemic and heart failure therapies.

\section{Abbreviations}

DM: Diabetes mellitus; FS: Fractional shortening; HG: High glucose; ICAM-1: Intercellular adhesion molecule-1; IL-1ß: Interleukin-1 13; LV: Left ventricular; LVEDD: Left ventricular end-diastolic dimension; LVEF: Left ventricular ejection fraction; LVESD: Left ventricular end-systolic dimension; NF-kB: Nuclear factor-kappaB; STZ: Streptozocin; TNF-a: Tumor necrosis factor-alpha;; TP: Triptolide; VCAM-1: Vascular cell adhesion molecule-1.

\section{Competing interests}

The authors declare that they have no competing interests.

\section{Authors' contributions}

$\mathrm{H}-\mathrm{LW}$ participated in design of the study, carried out animal drug administration, cell culture, immunohistochemistry, RT-PCR, western blot and Elisa analysis, and drafted the manuscript. Z-SL performed cardiac function measurement, analysis and interpretation of the data. RZ contributed to interpret the data and proofread the manuscript. KY participated in design and supervision of the study, analysis and interpretation of the data, statistical analysis, and critical revision of the manuscript. All authors have seen and approved the final manuscript.

\section{Author details}

${ }^{1}$ Department of Cardiology, The Third Xiangya Hospital of Central South University, No. 138 Tongzipo Road, Changsha, Hunan 410013, P.R.China. ${ }^{2}$ Department of Cardiology, Sichuan Academy of Medical Sciences \& Sichuan Provincial People's Hospital, No.32 West Second Section First Ring Road, Chengdu, Sichuan 610072, P.R.China. ${ }^{3}$ Department of Cardiovascular and Thoracic Surgery, The Seventh People's Hospital of Chengdu, No. 1 Twelfth Middle Street, Chengdu, Sichuan 610041, P.R.China.

Received: 4 January 2013 Accepted: 16 March 2013

Published: 25 March 2013 


\section{References}

1. Falcao-Pires I, Leite-Moreira AF: Diabetic cardiomyopathy: understanding the molecular and cellular basis to progress in diagnosis and treatment. Heart Fail Rev 2012, 17:325-344.

2. Hotamisligil GS: Inflammation and metabolic disorders. Nature 2006, 444:860-867.

3. Stratmann B, Tschoepe D: The diabetic heart: sweet, fatty and stressed. Expert Rev Cardiovasc Ther 2011, 9:1093-1096.

4. Ku PM, Chen LJ, Liang JR, Cheng KC, Li YX, Cheng JT: Molecular role of GATA binding protein 4 (GATA-4) in hyperglycemia-induced reduction of cardiac contractility. Cardiovasc Diabetol 2011, 10:57.

5. Lorenzo O, Picatoste B, Ares-Carrasco S, Ramírez E, Egido J, Tunon J: Potential role of nuclear factor $\mathrm{KB}$ in diabetic cardiomyopathy. Mediators Inflamm 2011, vol. 2011(Article ID 652097):9. doi:10.1155/2011/652097.

6. Teixeira-Lemos E, Nunes S, Teixeira F, Reis F: Regular physical exercise training assists in preventing type 2 diabetes development: focus on its antioxidant and anti-inflammatory properties. Cardiovasc Diabetol 2011, 10:12.

7. Liu Q: Triptolide and its expanding multiple pharmacological functions. Int Immunopharmacol 2011, 11:377-383.

8. Wong KF, Yuan Y, Luk JM: Tripterygium wilfordii bioactive compounds as anticancer and anti-inflammatory agents. Clin Exp Pharmacol Physiol 2012, 39:311-320.

9. Tao X, Cush JJ, Garret M, Lipsky PE: A phase I study of ethyl acetate extract of the chinese antirheumatic herb Tripterygium wilfordii hook F in rheumatoid arthritis. J Rheumatol 2001, 28:2160-2167.

10. Tao X, Younger J, Fan FZ, Wang B, Lipsky PE: Benefit of an extract of Tripterygium Wilfordii Hook F in patients with rheumatoid arthritis: a double-blind, placebo-controlled study. Arthritis Rheum 2002, 46:1735-1743.

11. Cibere J, Deng Z, Lin Y, Ou R, He Y, Wang Z, Thorne A, Lehman AJ, Tsang IK, Esdaile JM: A randomized double blind, placebo controlled trial of topical Tripterygium wilfordii in rheumatoid arthritis: reanalysis using logistic regression analysis. J Rheumatol 2003, 30:465-467.

12. Li R, Takazawa K, Suzuki H, Hariya A, Yamamoto T, Matsushita S, Hirose H, Amano A: Synergistic effect of triptolide and tacrolimus on rat cardiac allotransplantation. Jpn Heart J 2004, 45:657-665.

13. Liu Y, Chen Y, Liu FQ, Lamb JR, Tam PK: Combined treatment with triptolide and rapamycin prolongs graft survival in a mouse model of cardiac transplantation. Transpl Int 2008, 21:483-494.

14. Gao Q, Shen W, Qin W, Zheng C, Zhang M, Zeng C, Wang S, Wang J, Zhu X, Liu Z: Treatment of $\mathrm{db} / \mathrm{db}$ diabetic mice with triptolide: a novel therapy for diabetic nephropathy. Nephrol Dial Transplant 2010, 25:3539-3547.

15. Van Linthout S, Spillmann F, Riad A, Trimpert C, Lievens J, Meloni M, Escher F, Filenberg E, Demir O, Li J, Shakibaei M, Schimke I, Staudt A, Felix SB, Schultheiss HP, De Geest B, Tschope C: Human apolipoprotein A-I gene transfer reduces the development of experimental diabetic cardiomyopathy. Circulation 2008, 117:1563-1573.

16. Ares-Carrasco S, Picatoste B, Benito-Martin A, Zubiri I, Sanz AB, Sanchez-Nino MD, Ortiz A, Egido J, Tunon J, Lorenzo O: Myocardial fibrosis and apoptosis, but not inflammation, are present in long-term xperimental diabetes. Am J Physiol Heart Circ Physiol 2009, 297:H2109-2019.

17. Sun D, Shen M, Li J, Li W, Zhang Y, Zhao L, Zhang Z, Yuan Y, Wang H, Cao F: Cardioprotective effects of tanshinone IIA pretreatment via kinin B2 receptor-Akt-GSK-3b dependent pathway in experimental diabetic cardiomyopathy. Cardiovasc Diabetol 2011, 10:4.

18. Rajesh M, Mukhopadhyay P, Batkai S, Patel V, Saito K, Matsumoto S, Kashiwaya Y, Horvath B, Mukhopadhyay B, Becker L, Hasko G, Liaudet L, Wink DA, Veves A, Mechoulam R, Pacher P: Cannabidiol attenuates cardiac dysfunction, oxidative stress, fibrosis, and inflammatory and cell death signaling pathways in diabetic cardiomyopathy. J Am Coll Cardiol 2010, 56:2115-2125.

19. Snell-Bergeon JK, West NA, Mayer-Davis EJ, Liese AD, Marcovina SM, D'Agostino RB Jr, Hamman RF, Dabelea D: Inflammatory markers are increased in youth with type 1 diabetes: the SEARCH Case-control study. J Clin Endocrinol Metab 2010, 95:2868-2876.

20. Westermann D, Van Linthout S, Dhayat S, Dhayat N, Escher F, BückerGartner C, Spillmann F, Noutsias M, Riad A, Schultheiss HP, Tschope C: Cardioprotective and anti-inflammatory effects of interleukin converting enzyme inhibition in experimental diabetic cardiomyopathy. Diabetes 2007, 56:1834-1841.
21. Westermann D, Van Linthout S, Dhayat S, Dhayat N, Schmidt A, Noutsias M, Song XY, Spillmann F, Riad A, Schultheiss HP, Tschope C: Tumor necrosis factor-alpha antagonism protects from myocardial inflammation and fibrosis in experimental diabetic cardiomyopathy. Basic Res Cardiol 2007, 102:500-507.

22. Nian M, Lee P, Khaper N, Liu P: Inflammatory cytokines and postmyocardial infarction remodeling. Circ Res 2004, 94:1543-1553.

23. Kannel WB, McGee DL: Diabetes and cardiovascular disease. The Framingham study. JAMA 1979, 241:2035-2038.

24. ADVANCE Collaborative Group, Patel A, MacMahon S, Chalmers J, Neal B, Billot L, Woodward M, Marre M, Cooper M, Glasziou P, Grobbee D, Hamet P, Harrap S, Heller S, Liu L, Mancia G, Mogensen CE, Pan C, Poulter N, Rodgers A, Williams B, Bompoint S, de Galan BE, Joshi R, Travert F: Intensive blood glucose control and vascular outcomes in patients with type 2 diabetes. N Engl J Med 2008, 358:2560-2572.

25. Castagno D, Baird-Gunning J, Jhund PS, Biondi-Zoccai G, MacDonald MR, Petrie MC, Gaita F, McMurray JJ: Intensive glycemic control has no impact on the risk of heart failure in type 2 diabetic patients: evidence from a 37,229 patient meta-analysis. Am Heart J 2011, 162:938-948. e2.

26. Vaz Perez A, Doehner W, von Haehling S, Schmidt H, Zimmermann AV Volk HD, Anker SD, Rauchhaus M: The relationship between tumor necrosis factor- $a$, brain natriuretic peptide and atrial natriuretic peptide in patients with chronic heart failure. Int J Cardiol 2010, 141:39-43.

27. Miettinen KH, Lassus J, Harjola VP, Siirila-Waris K, Melin J, Punnonen KR, Nieminen MS, Laakso M, Peuhkurinen KJ: Prognostic role of pro- and anti-inflammatory cytokines and their polymorphisms in acute decompensated heart failure. Eur J Heart Fail 2008, 10:396-403.

28. Sun M, Chen M, Dawood F, Zurawska U, Li JY, Parker T, Kassiri Z, Kirshenbaum LA, Arnold M, Khokha R, Liu PP: Tumor necrosis factor-alpha mediates cardiac remodeling and ventricular dysfunction after pressure overload state. Circulation 2007, 115:1398-1407.

29. Mann DL, McMurray JJ, Packer M, Swedberg K, Borer JS, Colucci WS, Djian J, Drexler H, Feldman A, Kober L, Krum H, Liu P, Nieminen M, Tavazzi L, van Veldhuisen DJ, Waldenstrom A, Warren M, Westheim A, Zannad F, Fleming T: Targeted anticytokine therapy in patients with chronic heart failure: results of the Randomized Etanercept Worldwide Evaluation (RENEWAL). Circulation 2004, 109:1594-1602.

30. Chung ES, Packer M, Lo KH, Fasanmade AA, Willerson JT, Anti-TNF Therapy Against Congestive Heart Failure Investigators: Randomized, double-blind placebo-controlled, pilot trial of infliximab, a chimeric monoclonal antibody to tumor necrosis factor-alpha, in patients with moderate-tosevere heart failure: results of the anti-TNF Therapy Against Congestive Heart Failure (ATTACH) trial. Circulation 2003, 107:3133-3140

31. Gong $Y$, Xue $B$, Jiao J, Jing $L$, Wang $X$ : Triptolide inhibits COX-2 expression and PGE2 release by suppressing the activity of NF-kappaB and JNK in LPS-treated microglia. J Neurochem 2008, 107:779-788.

32. Kizelsztein P, Komarnytsky S, Raskin I: Oral administration of triptolide ameliorates the clinical signs of experimental autoimmune encephalomyelitis (EAE) by induction of HSP70 and stabilization of NF-kappaB//kappaBalpha transcriptional complex. J Neuroimmuno/ 2009, 217:28-37.

33. Wu Y, Cui J, Bao X, Chan S, Young DO, Liu D, Shen P: Triptolide attenuates oxidative stress, NF-kappaB activation and multiple cytokine gene expression in murine peritoneal macrophage. Int J Mol Med 2006, 17:141-150.

34. Lu Y, Bao X, Sun T, Xu J, Zheng W, Shen P: Triptolide attenuate the oxidative stress induced by LPS/D-GalN in mice. I Cell Biochem 2012, 113:1022-1033.

35. Li CJ, Lv L, Li H, Yu DM: Cardiac fibrosis and dysfunction in experimental diabetic cardiomyopathy are ameliorated by alpha-lipoic acid. Cardiovasc Diabetol 2012, 11:73.

36. Lee JE, Yi CO, Jeon BT, Shin HJ, Kim SK, Jung TS, Choi JY, Roh GS: Alphalipoic acid attenuates cardiac fibrosis in Otsuka Long-Evans Tokushima Fatty rats. Cardiovasc Diabetol 2012, 11:111.

37. Matta R, Wang X, Ge H, Ray W, Nelin LD, Liu Y: Triptolide induces antiinflammatory cellular responses. Am J Transl Res 2009, 1:267-282.

38. Wold LE, Ren J: Streptozotocin directly impairs cardiac contractile function in isolated ventricular myocytes via a p38 map kinasedependent oxidative stress mechanism. Biochem Biophys Res Commun 2004, 318:1066-1071. 
39. Katovich MJ, Hanley K, Strubbe G, Wright BE: Effects of streptozotocininduced diabetes and insulin treatment on blood pressure in the male rat. Proc Soc Exp Biol Med 1995, 208:300-306.

40. Zhang $X$, Chen C: A new insight of mechanisms, diagnosis and treatment of diabetic cardiomyopathy. Endocrine 2012, 41:398-409.

41. Kumar S, Singh R, Vasudeva N, Sharma S: Acute and chronic animal models for the evaluation of anti-diabetic agents. Cardiovasc Diabetol 2012, 11:9.

doi:10.1186/1475-2840-12-50

Cite this article as: Wen et al: Anti-inflammatory effects of triptolide improve left ventricular function in a rat model of diabetic cardiomyopathy. Cardiovascular Diabetology 2013 12:50.

\section{Submit your next manuscript to BioMed Central and take full advantage of:}

- Convenient online submission

- Thorough peer review

- No space constraints or color figure charges

- Immediate publication on acceptance

- Inclusion in PubMed, CAS, Scopus and Google Scholar

- Research which is freely available for redistribution 